\title{
Mass Media Social Marketing Campaigns: A Practitioners Perspective
}

\author{
Patrick van Esch $^{1}$, Darejan Tsartsidze ${ }^{2} \&$ Linda Jean van Esch $^{3}$ \\ ${ }^{1}$ Southern Cross Business School, Southern Cross University, Queensland, Australia \\ ${ }^{2}$ Tbilisi State University \& German University of Administrative Sciences, Speyer, Germany \\ ${ }^{3}$ Western Australian School of Mines, Faculty of Science \& Engineering, Curtin University, Perth, Australia \\ Correspondence: Patrick van Esch, Southern Cross Business School, Southern Cross University, Locked Mail \\ Bag 4, Coolangatta, QLD 4225, Australia. Tel: 61-7-5589-3043. E-mail: vesch54@hotmail.com
}

Received: July 23, 2014 Accepted: August 11, 2014 Online Published: September 28, 2014

doi:10.5539/ijms.v6n5p40 URL: http://dx.doi.org/10.5539/ijms.v6n5p40

\begin{abstract}
This paper explores mass media social marketing practitioner perspectives of the intersect where the dimensions of religion taxonomy and mass media social marketing campaigns meet. Under an interpretive paradigm (Crotty, 1998), in-depth interviews were conducted with five expert mass media social marketing practitioners in Australia. The data was analysed qualitatively with the data analysis software package NVivo. Five themes emerged from the results: (1) The dimension of religion taxonomy does have application in mass media social marketing campaigns; (2) The use of a 'patriarch' in mass media social marketing campaigns and the possible implications; (3) The use of fantasy as a driver for voluntary behaviour change; (4) The assurance of salvation as a driver for voluntary behaviour change and (5) The consideration to use Jung Theory in mass media social marketing campaigns and the possible implications.
\end{abstract}

Keywords: dimensions of religion, in-depth interviews, mass media social marketing campaigns, Nvivo software, tree map analysis, qualitative research

\section{Introduction}

Founded in an earlier paper (Van Esch \& Van Esch, 2013); both the dimensions of religion and mass media social marketing campaigns continue to receive growing attention in the literature. The analysis and review of mass media social marketing campaigns is a continuation of the body of work founded in Van Esch et al. (2013) and the analysis of social marketing campaign texts has recently been reported and founded in Van Esch et al. (2014). The data was collected from five expert mass media social marketing practitioners who were identified from government and/or private agencies that specialise in the design, creation and evaluation of mass media social marketing campaigns and who have been directly related to or have experienced the topic under investigation. Due to the fact that only a small sample size has had interaction with the emerging topic, demographic data has been deliberately omitted to protect the anonymity of the research participants.

\section{Theoretical Foundations}

The intent of this study was to explore the relationship between the dimensions of religion and mass media social marketing and particularly, how to draw on and incorporate aspects of the dimensions of religion (i.e. a classification system in the field of religious studies) and how it may fit the social marketing framework as a means of influencing decision making processes in an attempt to drive mass voluntary behaviour change. Furthermore, it could be argued that the relationship under investigation may impact an element of culture that pervades every aspect of a society. Therefore, its effect on behaviour cannot be underestimated by marketers (Fam, Waller, \& Erdogan, 2002).

\subsection{Religion and Its Dimensions}

Fam, Waller and Erdogan (2002) continue to argue that "in a constantly changing and increasingly globalized world, religion still plays a significant role in influencing consumer behaviour". Religious beliefs play a significant part in sculpting social behaviour. Differences in religious affiliations, $74 \%$ of Australia's population reported having a religious affiliation (ABS, 2004; 2006), 77\% of Britain's population reported belonging to a religion (ONS, 2001) whilst 79.9\% of America's population indicated they had a religious identification (Kosmin and Keysar, 2008), tend to influence the way people live, the choices they make, what they eat and whom they 
associate with. According to Hirschman (1983), religious affiliations help shape attitudes towards dancing, magazines, restaurants and political ideas. According to Fam, Waller and Erdogan (2002), the influence of religious beliefs on individual and social behaviour is well documented (Anand and Kumar, 1982; Birch et al., 2001; Greeley, 1977; Hirschman, 1983; LaBarbera, 1987; Luqmani et al., 1987; McDaniel and Burnett, 1990; Michell and Al-Mossawi, 1999; Uppal, 1986; Waller and Fam, 2000;). However, only a handful of studies have somewhat examined the influence of the dimensions of religion (Table 1) on marketing communications.

Table 1. The dimensions of religion and their identifiers

\begin{tabular}{|c|c|}
\hline Dimension & Identifiers \\
\hline $\begin{array}{l}\text { Practical and } \\
\text { ritual }\end{array}$ & $\begin{array}{l}\text { Practices and rituals of different traditions and cultures, preaching, prayers, ceremonies, meditation, worship, spiritual } \\
\text { awareness, ethical insight, communities re-enacting their myths and stories to confirm and express beliefs through } \\
\text { action. }\end{array}$ \\
\hline $\begin{array}{l}\text { Experiential and } \\
\text { emotional }\end{array}$ & $\begin{array}{l}\text { Evoking religious feelings, direct experiences of the divine, visions, enlightenment, security, comfort, awe, inexplicable } \\
\text { presence, mystery, ecstasy, dread, guilt, awe, devotion, liberation, inner peace, bliss, assurance of salvation, brilliant } \\
\text { emptiness, an expanded sense of identity, accumulation of religious knowledge and experiences and unconscious, } \\
\text { super-conscious and/or neurologically induced events of a higher reality. }\end{array}$ \\
\hline $\begin{array}{l}\text { Narrative or } \\
\text { mythic }\end{array}$ & $\begin{array}{l}\text { Myths or sacred stories, systematic or complete interpretation of god(s), the nature of humans and their place in the } \\
\text { universe, historical accounts, hagiography, oral traditions, authority from the divine. }\end{array}$ \\
\hline $\begin{array}{l}\text { Doctrinal and } \\
\text { philosophical }\end{array}$ & $\begin{array}{l}\text { Doctrines, systematic formulation of religious teachings and beliefs, sacred texts, the nature of divinity, ultimate reality, } \\
\text { the relationship of humans to an ultimate, real, divinity. Religious narrate, reflection, structured beliefs beyond the } \\
\text { symbolic aspect of myths, faith, and values of a tradition, worldly views and salvation. }\end{array}$ \\
\hline Ethical and legal & $\begin{array}{l}\text { Laws, rules, guidelines or behavioural precepts for conduct according to which the community, employees, employers, } \\
\text { consumers, producers and citizens at every level of existence judge a person, conformity, a supernatural realm and } \\
\text { higher being of a particular faith. }\end{array}$ \\
\hline $\begin{array}{l}\text { Social and } \\
\text { institutional }\end{array}$ & $\begin{array}{l}\text { Tradition, belief system, social organisation, shared and implied attitudes practiced by individuals or the group, } \\
\text { community membership, participation in public, exemplary individuals, buildings, works of art, cities, symbols, idols, } \\
\text { other creations and places of worship, formally organised, a sense of normative values, group bonding, functioning } \\
\text { society and a community to live in. }\end{array}$ \\
\hline The material & $\begin{array}{l}\text { Ordinary objects or places that symbolise or manifest in material form that help connect the believer to the sacred, } \\
\text { supernatural or the divine, religious artefacts, religious capital, sacred objects, sacred tourism, pilgrimage and sacred } \\
\text { areas and/or places. }\end{array}$ \\
\hline
\end{tabular}

Source: Smart, 1996.

\subsection{Mass Media Social Marketing}

Kotler and Zaltman (1971) first coined the term social marketing as a reference for the application of marketing as a solution to social and health problems (MacFadyen, Stead, \& Hastings, 1999). Seminal works on the topic draws from different bodies of knowledge such as anthropology, communications theory, psychology and sociology in order to understand how to influence people's behaviour (Kotler \& Zaltman, 1971; MacFadyen, Stead \& Hastings, 1999). However, as social marketing has evolved, so too has its definition. French et al (2010) recognise that the social marketing discipline derives from two (2) distinct movements: (1) marketing and (2) social sciences. Both movements are concerned with how best to influence people's behaviour and hence their convergence informs mass media social marketing.

\subsection{In-Depth Interviews}

In-depth interviews were used as a qualitative research technique, to conduct individual interviews to explore experiences, ideas, opinions, perspectives, thoughts and views of five informed experts possessing knowledge of mass media social marketing campaigns and the dimensions of religion. Under the principle of saturation, Jette, Grover and Kech (2003) argue that expertise in a chosen topic can reduce the number of participants needed in a study. Therefore, to bolster the analysis and findings of the textual analysis founded in Van Esch et al., (2014), and to further distil any emerging themes from the data in order to draw meaningful conclusions, the in-depth interviews consisted of eight questions (Table 2). 
Table 2. In-depth interview questions

\begin{tabular}{|c|c|}
\hline \multicolumn{2}{|r|}{ Research Proposition 1: Are the seven dimensions of religion currently used or identified within mass media social marketing campaigns? } \\
\hline Question 1 & Does the dimension of religion taxonomy have application in mass media social marketing campaigns? \\
\hline Question 2 & mpaigns often use a preaching context; do you think this is related to religious practices? \\
\hline Question 3 & Is a preaching context an appropriate driver for mass voluntary behaviour change? \\
\hline Question 4 & $\begin{array}{l}\text { Some campaigns utilise a theme of Assurance of Salvation without using explicit religious language; do you think the campaign } \\
\text { would benefit or suffer from the use of religious language? }\end{array}$ \\
\hline Question 5 & Is an Assurance of Salvation theme an appropriate driver for mass voluntary behaviour change? \\
\hline \multicolumn{2}{|r|}{$\begin{array}{l}\text { Research proposition 2: What reception, understanding, openness to consider, do managers of social marketing campaigns have to a } \\
\text { clearly articulated description of the application of the dimensions of religion? }\end{array}$} \\
\hline Question 6 & $\begin{array}{l}\text { Whilst five of the seven dimensions were evident, many of the identifiers were not; would the increased use of the identifiers in } \\
\text { an implicit and/or explicit way reinforce a campaign message? }\end{array}$ \\
\hline Question 7 & $\begin{array}{l}\text { Two dimensions that are explicit in religious content were not evident in the campaigns; would this represent a deliberate extent } \\
\text { to mitigate the use of Religion in mass media social marketing campaigns? }\end{array}$ \\
\hline Question 8 & $\begin{array}{l}\text { The two non-evident dimensions: The Material and Narrative or Mythic, do they or their identifiers have application within } \\
\text { mass media social marketing campaigns? }\end{array}$ \\
\hline
\end{tabular}

Source: Van Esch et al., 2014.

Therefore, intentionally using more than one method of analysing data, the in-depth interviews were used to synthesise the data (Reiman, 1979); this approach allowed the individual methods to complement each other and the comparison used to triangulate the findings and add validity in drawing meaningful implications and conclusions.

\section{Interview Results and Discussion}

The first five questions focus on addressing the research proposition: 'are the seven dimensions of religion currently used or identified within mass media social marketing campaigns?'

\subsection{Does the Dimension of Religion Taxonomy Have Application in Mass Media Social Marketing Campaigns?}

The participants were asked if one or more of the dimensions of religion have application in mass media social marketing campaigns. Key responses:

"Yes, specifically symbols or myths that are used as subliminal stimuli portraying an experience that can influence the betterment of the campaigns target audience (Participant 1). "Yes, provided that it is in context within today's reality. The campaigns that use preaching generally are connected to a patriarchal figure. This may have a good influence on some people, but; this is only one sided. On the other side, the context of messages or visualisation of the patriarch may anger some audience members. Therefore, plenty of consideration must be given to such a dynamic during the planning phase of the campaign" (Participant 2). "From a modern view, it is very sensitive. They would need to be very flexible and be able to fit with the different non-religious values that people align to. I think that they should never be used within a campaign to bring about a bad reaction in people or cause aggression, as this would be detrimental to the success of the campaign and potentially to a society that is united by religion" (Participant 3). "Rituals and especially the social and institutional aspect; which are very important factors when planning campaigns. Not only are religious themes important but more so their integration with technology and how that links with the audience" (Participant 4). "The 'doctrinal and philosophical' and especially the 'practical and ritual' dimensions are expected in campaigns. The Narrative or mythic assists with campaigns focused on driving social responsibility on a broader scale. It is a balance because too much emphasis incorporating religious vocabulary or religious direction may damage the campaign message and ultimately anger or put the target audience offside" (Participant 5).

The results indicate that the dimension of religion taxonomy does have application in mass media social marketing campaigns. However, there was not full committal to all of the dimensions rather specific and targeted dimensions. Furthermore, there is a hesitation or caution to their use as to ensure that there is not a negative effect on the target audience. Interestingly, the role that a patriarch plays in a campaign was noted. Even when referencing back to the literature, this is the first time this theme has emerged.

\subsection{The Campaigns Often Use a 'Preaching' Context; Do You Think This Is Related to Religious Practices?}

The participants were asked if a preaching context is related to religious practices. Key responses:

"I think it may also be seen as lecturing but I can't say that the success of the campaign depends on a preaching context. In terms of marketing, a preaching context is not necessarily or deliberately linked to any religious 
practices" (Participant 1). "Preaching can incite some kind of fears in the human psyche. The preaching may use an apathetical vocabulary and therefore I don't think that this is related to religious practices. If it is, I think it must be a coincidence" (Participant 2). "It may be some kind of call to action but for me it's not preaching" (Participant 3). "In general there is some kind of calling, but I don't know how much it can be attributed to preaching. Maybe theoretically it has religious dependence" (Participant 4). "Preaching may be used as a call to action when you are explaining what is good and what is not. When using preaching in social marketing, the characteristics of the dimensions of religion may instil loyalty towards the desired behaviour change over time; this would need to be tested" (Participant 5).

The results indicate that a preaching context is not related to religious practices. It appears that 'preaching' is not considered as a campaign communication technique; rather the focus is on the call to action which can be achieved through different mediums.

\subsection{Is a Preaching Context an Appropriate Driver for Mass Voluntary Behaviour Change?}

The participants were asked if a preaching context was an appropriate driver for mass voluntary behaviour change. Key responses:

"I think it is in general and to get into an individual's subconscious, it really is. There are many people who believe in the power of preaching and the influence it can have. But it is really dangerous to attempt to manipulate target audiences with faith based phrases" (Participant 1). "Whilst theoretical, social marketing communication needs to be clear and precise to assist with the effect the message will have on an audience. Generally, this is not discussed during the campaign planning process. We are currently exploring the use of Jung Theory with the archetypal notion that within everyone's general subconscious, there are some archetypes, specifically we are looking at the links with fantasy and the effect that will have on behaviour change" (Participant 2). "It may cause a positive influence but I can't say for sure" (Participant 3). "Preaching as a call to action may cause some behaviour changes, but I can't say it will categorically. In most cases people dislike being told what to do and how to behave, especially by someone who appears to be self-righteous. This could have an effect on the success of the campaign" (Participant 4). "Absolutely, an affiliation with an influencer or mentor will drive a call to action especially if what they are saying is believable" (Participant 5).

The results indicate that on its own, a preaching context is not considered a driver for behaviour change, yet combined with other techniques and in certain circumstances; it may assist with achieving a desired behavioural change. Interestingly, two new themes emerge: (1) consideration of using and/or linking 'Jung Theory' to mass media social marketing campaigns and stemming from that (2) the use of 'fantasy' and the effect that it may have on voluntary behaviour change. Referencing back to the literature, this is the first time these two themes have emerged.

3.4 Some Campaigns Utilise a Theme of 'Assurance of Salvation' without Using Explicit Religious Language; Do You Think a Campaign Would Benefit or Suffer from the Use of Religious Language?

The participants were asked if campaigns would benefit or suffer from the use of religious language. Key responses:

"In most religions, the believer receives salvation through good deeds or good works. If salvation is assured, then the link to the campaign audience will be for them to conduct good works or a good deed which means that the communication method does not necessarily need to be expressed through religious language" (Participant 1). "Hypothetically everyone wants to be saved. In terms of health, it is being physically saved. A campaign does not necessarily have to use religious language, rather religious rituals to drive the behaviour change. It does not need to be explicit when the want of salvation in our culture is really high" (Participant 2). "Religious language and religious themes can be used to manipulate an audience to create a religious euphoria. This technique is used in political campaigns. It is the level of sincerity in which the religious vocabulary is used that will always be in question" (Participant 3). "Salvation is a really difficult theme to use within a message especially if it is explicitly enforced with religious language. It would have to be a really great and carefully constructed message or maybe the slogan could be loaded with religious language. I think that industry would consider this far too risky" (Participant 4). "Yes, it should be very active. If you don't modify your behaviour, you won't be saved. This can be perfectly translated through social marketing” (Participant 5).

The results indicate a divided view on the application of religious language in campaigns. Rather, the divide appears to be the objection to the explicit use rather than the religious language itself. This objection stems from the perceived view that religion or religious application within a campaign is considered risky and may cause a negative response from the target audience. 


\subsection{Is an 'Assurance of Salvation' Theme an Appropriate Driver for Mass Voluntary Behaviour Change?}

The participants were asked if the assurance of salvation was an appropriate driver for mass voluntary behaviour change. Key responses:

"Yes, it might cause a change in behaviour but I think it may not be as successful as one would think. Who can actually guarantee salvation, if salvation is not achieved, this could have a negative reaction from the target audience" (Participant 1). "I can't answer unequivocally on this question. It would be situational and heavily dependent on the type of desired behaviour change" (Participant 2). "Assurance of salvation, this is a simple PR trick. It may cause some changes, especially for those, who are positively affected by the contents of the campaign" (Participant 3). "It may be a reason to change an individual's behaviour; ultimately everybody wants to be saved" (Participant 4). "Yes of course, especially if being saved is the reason for changing someone's behaviour" (Participant 5).

The results indicate that 'Assurance of Salvation' is considered a driver for mass voluntary behaviour change. However, there was trepidation as to how much behaviour change could actually occur.

The next three questions focus on addressing the research proposition: 'what reception, understanding, openness to consider, do managers of social marketing campaigns have to a clearly articulated description of the application of the dimensions of religion?'

3.6 Whilst Five of the Seven Dimensions Were Evident, Many of The Identifiers Were Not; Would the Increased Use of the Identifiers in an Implicit and/or Explicit Way Reinforce a Campaign Message?

The participants were asked whether an increase in the identifiers in an implicit/explicit way would reinforce a campaign message. Key responses:

"If there is a link between the seven (7) dimensions and social marketing, then it would be imperative that the dimensions are realised to their full potential. Ultimately it would be the dimensions reinforcing a campaign message which should then include all of the identifiers" (Participant 1). "I would also research the influence of each dimension individually as well as all of them as a whole on a selected audience. And as a side topic, further explore religious value within social marketing. Maybe the identifiers on their own merit could have an impact on the campaign message. Again, this would need to be tested" (Participant 2). "One could argue that if the dimensions identified are not having the desired impact, it could be attributable to a lack of support from the identifiers. You would have to imbed both the dimensions and identifiers within a campaign and test if they are a justifiable reinforcement method" (Participant 3). "If the framework of the campaign is based on the dimensions, then yes; the identifiers must also form part of that framework" (Participant 4). "For me, the most obscure is the ethical and legal dimension. The dimension does not hold unless all of the identifiers are included. I imagine that this would be the case for the other dimensions as well" (Participant 5).

The results indicate that the addition of the identifiers should be used to reinforce the application of the particular dimensions used within the campaign rather than the addition of the identifiers having a direct application of reinforcing the campaign message. This further implies that for a dimension to be present or effective the identifiers must be increased or furthermore, all of the identifiers present.

3.7 Two Dimensions that Are Explicit in Religious Content Were Not Evident in the Campaigns; Would This Represent a Deliberate Intent to Mitigate the Use of 'Religion' in Mass Media Social Marketing Campaigns?

The participants were asked if in practice, there is a deliberate intent to mitigate the use of religion in mass media social marketing campaigns. Key responses:

"Yes of course. But it may also be the case when the segment is not aimed at religious people" (Participant 1). "Yes it is deliberate. It is to ensure that the campaign does not receive a bad reaction from the audience. There are many religions, all with their different nuances, all of which culminates into a very contentious topic; especially if it is being used to drive mass behaviour change" (Participant 2). "The deliberate omission of the two dimensions is used to create a cynical dependence towards religion; this in turn could be used to cause aggression from audiences that are less religious" (Participant 3). "It's not deliberate, this only happens when your target audience is less religious, or there are no common links between religion and the desired outcome" (Participant 4). "Yes it's deliberate. I also suspect that the evident dimensions were not deliberately constructed to be part of the campaigns during the planning phase" (Participant 5).

The results indicate that the views are mixed. Some participants say that campaigns are deliberately designed to mitigate the use of 'Religion' in mass media social marketing campaigns. Primarily it is mitigated to minimise a negative response from the target audience. 
3.8 The Two Non-Evident Dimensions: 'The Material' and 'Narrative or Mythic', Do They Or Their Identifiers Have Application within Mass Media Social Marketing Campaigns?

The participants were asked if two specific dimensions and their identifiers have application within mass media social marketing campaigns. Key responses:

"I can't see how the material dimension would have much of an impact. However, if preaching is used for message communication, then there are strong parallels with the Narrative dimension, especially when the communication involves a patriarch. I think the mythic aspect used correctly could be extremely powerful" (Participant 1). "Myths should be very active within social marketing campaigns. It is a tool that can be easily used to take an audience on a journey to reach a desired outcome" (Participant 2). "Yes. If the seven dimensions are the platform then all of the dimensions should be included. Based on empirical facts, myths are very important in marketing and are often one of the first steps of branding" (Participant 3). Religious symbols are often used in mass media campaigns. Whilst you can't always see these symbols, they are imbedded in the myths. I am surprised that the campaigns did not include any aspects of the mythic dimension" (Participant 4). "The identifiers within the material dimension are centred on being sacred. These identifiers used correctly could have a significant impact on the success of a campaign" (Participant 5).

The results indicate that the 'Narrative or Mythic' dimension should have application in mass media social marketing campaigns, especially when the dimensions of religion are to be used as the framework.

\section{Tree Map Analysis and Discussion}

The interviews were subjected to further qualitative analysis (Perry, 1995: 22-23; Veal, 2005: 25) using the qualitative software tool Nvivo. This analysis included a tree map analysis of each individual interview and was conducted to further distil the data and to identify if any additional themes had emerged.

\subsection{Tree Map Analysis - Interview 1}

The interview was subjected to a tree map analysis of the seven dimensions of religion and the identifiers within them. Table 3 below shows the results.

Table 3. Tree Map Analysis - Interview 1

\begin{tabular}{lcc}
\hline Nodes & Coding references & Items coded \\
\hline Practical and Ritual\Preaching & 10 & 3 \\
Social and Institutional\Exemplary individuals & 6 & 4 \\
Experiential and Emotional\Assurance of salvation & 6 & 3 \\
Doctrinal and Philosophical\Religious narrative & 6 & 2 \\
Experiential and Emotional\Comfort & 5 & 2 \\
Experiential and Emotional\Evoking religious feelings & 5 & 2 \\
Practical and Ritual\Re-enactment of myths and stories & 2 & 1 \\
The Material\Religious artefacts & 2 & 1 \\
Social and Institutional\Participation in public & 1 & 1 \\
The Material\Symbolise & 1 & 1 \\
\hline
\end{tabular}

Source: Developed for this research.

The results from the tree map analysis indicate the dimensions and the identifiers within them.

Strong presence:

- $\quad$ Experimental and Emotional - Assurance of salvation, comfort and evoking religious feelings.

Medium presence:

- Practical and Ritual - Preaching and re-enactment of myths and stories

- Social and Institutional - Exemplary individuals and participation in public

- $\quad$ The material - Religious artefacts and symbolise.

Low presence:

- $\quad$ Doctrinal and Philosophical - Religious narrative.

4.2 Tree Map Analysis - Interview 2

The interview was subjected to a tree map analysis of the seven dimensions of religion and the identifiers within 
them. Table 4 below shows the results.

Table 4. Tree map analysis - Interview 2

\begin{tabular}{|c|c|c|}
\hline Nodes & Coding references & Items coded \\
\hline Social and Institutional $\backslash$ Exemplary individuals & 18 & 9 \\
\hline Practical and Ritual\Preaching & 11 & 6 \\
\hline Experiential and Emotional $\backslash$ Assurance of salvation & 10 & 3 \\
\hline Doctrinal and Philosophical\Religious narrative & 9 & 4 \\
\hline Doctrinal and Philosophical $\backslash$ Worldly views & 7 & 1 \\
\hline Social and Institutional $\backslash$ Symbols & 6 & 3 \\
\hline Experiential and Emotional\Evoking religious feelings & 6 & 2 \\
\hline Practical and Ritual $\mid$ Ceremonies & 5 & 3 \\
\hline Doctrinal and Philosophical $\mid$ Salvation & 4 & 1 \\
\hline Doctrinal and Philosophical|Doctrines & 3 & 3 \\
\hline Practical and Ritual $\backslash$ Rituals & 2 & 2 \\
\hline Doctrinal and Philosophical $\backslash$ Values of a tradition & 2 & 1 \\
\hline Experiential and Emotional $\backslash$ Accumulation of religious knowledge & 2 & 1 \\
\hline Ethical and Legal $\backslash$ Judgement of a person & 2 & 1 \\
\hline Social and Institutional\Participation in public & 2 & 1 \\
\hline Doctrinal and Philosophical Symbolic aspect of myths & 1 & 1 \\
\hline Social and Institutional $\backslash$ Community membership & 1 & 1 \\
\hline Social and Institutional\Re-enactment of myths and stories & 1 & 1 \\
\hline Social and Institutional $\mid$ Social organisation & 1 & 1 \\
\hline
\end{tabular}

Source: Developed for this research.

The results from the tree map analysis indicate the dimensions and the identifiers within them.

Strong presence:

- Social and Institutional - Exemplary individuals, symbols, participation in public, community membership, re-enactment of myths and stories and social organisation

- Doctrinal and Philosophical - Religious narrative, worldly views, salvation, doctrines, value of a tradition and the symbolic aspect of myths.

Medium presence:

- Practical and Ritual - Preaching, ceremonies and rituals

- Experiential and Emotional - Assurance of salvation, evoking religious feelings, accumulation of religious knowledge.

Low presence:

- $\quad$ Ethical and Legal - Judgement of a person.

4.3 Tree Map Analysis - Interview 3

The interview was subjected to a tree map analysis of the seven dimensions of religion and the identifiers within them. Table 5 below shows the results.

Table 5. Tree map analysis - Interview 3

\begin{tabular}{lcc}
\hline Nodes & Coding references & Items coded \\
\hline Practical and Ritual\Preaching & 13 & 6 \\
Social and Institutional\Exemplary individuals & 13 & 4 \\
Doctrinal and Philosophical\Religious narrative & 9 & 4 \\
Experiential and Emotional\Evoking religious feelings & 4 & 2 \\
The Material/Religious artefacts & 3 & 1 \\
Practical and Ritual\Ceremonies & 1 & 1 \\
Practical and Ritual\Re-enactment of myths and stories & 1 & 1 \\
Experiential and Emotional\Comfort & 1 & 1 \\
Doctrinal and PhilosophicallSymbolic aspects of myths & 1 & 1 \\
Social and Institutional\Participation in public & 1 & 1 \\
\hline
\end{tabular}

Source: Developed for this research. 
The results from the tree map analysis indicate the dimensions and the identifiers within them.

Strong presence:

- $\quad$ Practical and Ritual - Preaching, ceremonies and re-enactment of myths and stories.

Medium presence:

- Social and Institutional - Exemplary individuals and participation in public

- Doctrinal and Philosophical - Religious narrative and symbolic aspects of myths

- Experimental and Emotional - Evoking religious feelings and comfort.

Low presence:

- $\quad$ The Material - Religious artefacts.

4.4 Tree Map Analysis - Interview 4

The interview was subjected to a tree map analysis of the seven dimensions of religion and the identifiers within them. Table 6 below shows the results.

Table 6. Tree map analysis - Interview 4

\begin{tabular}{lcc}
\hline Nodes & Coding references & Items coded \\
\hline Social and Institutional\Exemplary individuals & 16 & 8 \\
Narrative and Mythic $\backslash$ Myths or sacred stories & 10 & 7 \\
Practical and Ritual\Preaching & 9 & 6 \\
The Material\Religious artefacts & 6 & 3 \\
Ethical and Legal\Rules & 4 & 4 \\
Practical and Ritual\Ceremonies & 1 & 1 \\
Doctrinal and Philosophical\Religious narrative & 1 & 1 \\
Social and Institutional\Community membership & 1 & 1 \\
Social and Institutional\Participation in public & 1 & 1 \\
\hline
\end{tabular}

Source: Developed for this research.

The results from the tree map analysis indicate the dimensions and the identifiers within them.

Strong presence:

- $\quad$ Social and Institutional - Exemplary individuals, community membership and participation in public.

Medium presence:

- $\quad$ Practical and Ritual - Ceremonies.

Low presence:

- Narrative or Mythic - Myths or sacred stories

- The material - Religious artefacts

- $\quad$ Ethical and legal - Rules

- Doctrinal and philosophical - Religious narrative.

4.5 Tree Map Analysis - Interview 5

The interview was subjected to a tree map analysis of the seven dimensions of religion and the identifiers within them. Table 7 below shows the results. 
Table 7. Tree map analysis - Interview 5

\begin{tabular}{|c|c|c|}
\hline Nodes & Coding references & Items coded \\
\hline Social and Institutional|Exemplary individuals & 21 & 9 \\
\hline Practical and Ritual $\backslash$ Preaching & 15 & 6 \\
\hline Experiential and Emotional\Evoking religious feelings & 11 & 9 \\
\hline Practical and Ritual $\mid C e r e m o n i e s$ & 6 & 3 \\
\hline Ethical and Legal\Behavioural precepts for conduct & 3 & 2 \\
\hline Ethical and Legal $\backslash$ Guidelines & 2 & 1 \\
\hline Experiential and Emotional $\backslash$ Comfort & 1 & 1 \\
\hline Experiential and Emotional $\backslash$ Assurance of salvation & 1 & 1 \\
\hline Doctrinal and Philosophical $\backslash$ Religious narrative & 1 & 1 \\
\hline Doctrinal and Philosophical|Doctrines & 1 & 1 \\
\hline Ethical and Legal $\backslash$ Rules & 1 & 1 \\
\hline Social and Institutional Social organisation & 1 & 1 \\
\hline Social and Institutional $\backslash$ Group bonding & 1 & 1 \\
\hline Social and Institutional\Participation in public & 1 & 1 \\
\hline Social and Institutional/Functioning society & 1 & 1 \\
\hline
\end{tabular}

Source: Developed for this research.

The results from the tree map analysis indicate the dimensions and the identifiers within them.

Strong presence:

- Social and Institutional - Exemplary individuals, social organisation, group bonding, participation in public and functioning society.

Medium presence:

- Experiential and Emotional - Evoking religious feelings, comfort and assurance of salvation

Low presence:

- $\quad$ Practical and ritual - Preaching and ceremonies

- Doctrinal and philosophical - Religious narrative and doctrines.

4.6 Tree Map Analysis - All Interviews

The interviews as a whole were subjected to a tree map analysis of the seven dimensions of religion and the identifiers within them. Table 8 below shows the results.

Table 8. All interviews - Tree map analysis - All interviews

\begin{tabular}{|c|c|c|}
\hline Nodes & Coding references & Items coded \\
\hline Social and Institutional $\backslash$ Exemplary individuals & 48 & 19 \\
\hline Practical and Ritual $\backslash$ Preaching & 45 & 19 \\
\hline Doctrinal and Philosophical $\backslash$ Religious narrative & 41 & 16 \\
\hline Experiential and Emotional\Assurance of salvation & 33 & 17 \\
\hline Practical and Ritual $\backslash$ Ceremonies & 21 & 9 \\
\hline Experiential and Emotional\Evoking religious feelings & 16 & 4 \\
\hline Experiential and Emotional \Comfort & 13 & 7 \\
\hline Ethical and Legal $\backslash$ Guidelines & 7 & 5 \\
\hline Social and Institutional $\backslash$ Participation in public & 6 & 4 \\
\hline Social and Institutional $\backslash$ Group bonding & 5 & 1 \\
\hline Social and Institutional lCommunity membership & 5 & 2 \\
\hline Practical and Ritual $R$ Re-enactment of myths and stories & 4 & 2 \\
\hline Ethical and Legal Rules & 4 & 3 \\
\hline Doctrinal and Philosophical Symbolic aspect of myths & 4 & 4 \\
\hline Ethical and Legal Judgment of a person & 4 & 4 \\
\hline Practical and Ritual\Ethical insight & 3 & 2 \\
\hline The Material\Religious artefacts & 2 & 1 \\
\hline
\end{tabular}

Source: Developed for this research. 
The results from the tree map analysis indicate the dimensions and the identifiers within them.

Strong presence:

- $\quad$ Social and Institutional - Exemplary individuals, participation in public, group bonding and community membership

- $\quad$ Practical and Ritual - Preaching, ceremonies, re-enactment of myths and stories and ethical insight.

Medium presence:

- Experiential and emotional - Assurance of salvation, evoking religious feelings and comfort

- Ethical and legal - Guidelines, rules and judgement of a person

Low presence:

- $\quad$ The material - Religious artefacts.

\section{Key Themes Emerging from the Results}

Table 9 below summarises the emergent themes and contribution to knowledge that has been realised from the comparison of the results from both the in-depth interviews and the qualitative analysis from this research. The following approach has been adopted in classifying the contribution to knowledge of this research:

- If a research output did not have a counterpart in the existing literature, it is classified as 'advance to current knowledge'

- If there was a similarity with the existing literature, the research output has been classified as 'addition to current knowledge'

- If there was a direct link with the existing literature, the research output has been classified as 'confirmation of current knowledge'.

Table 9. Summary of contribution to knowledge of this research

\begin{tabular}{ll}
\hline Research Proposition 1: Are the seven dimensions of religion currently used or identified within mass media social marketing campaigns? \\
\hline Output & Contribution \\
\hline The dimension of religion taxonomy does have application in mass media social marketing & Advance to current knowledge \\
campaigns & \\
The use of a patriarch in mass media social marketing campaigns and the possible implications & Advance to current knowledge \\
The consideration for the use of fantasy as a driver for voluntary behaviour change & Advance to current knowledge \\
$\begin{array}{l}\text { Assurance of salvation as a theme is considered a driver for voluntary behaviour change } \\
\text { The consideration to use Jung Theory in mass media social marketing campaigns and the }\end{array}$ & Addition to current knowledge \\
possible implications & Addition to current knowledge \\
\hline
\end{tabular}

Research proposition 2: What reception, understanding, openness to consider, do managers of social marketing campaigns have to a clearly articulated description of the application of the dimensions of religion?

\begin{tabular}{ll}
\hline Output & Contribution \\
\hline Religion or religious application within a campaign is considered risky & Confirmation of current knowledge \\
There is a deliberate intent to mitigate the use of religion in mass media social marketing & Confirmation of current knowledge \\
campaigns. &
\end{tabular}

Source: Developed for this research.

\section{Conclusion}

This research explored five practitioners' views on the intersect where the dimensions of religion and mass media social marketing campaigns meet. Several key themes emerge from the results. Of those themes, three contribute to an advance in current knowledge, two contribute to an addition in current knowledge and the final two confirm current knowledge. As with most research, this study is limited in a number of ways. In particular, the sample of expert mass media social marketing campaign practitioners is relatively small (Creswell, 1998: 122). This means that the emerging findings from the qualitative analysis require further exploration and validation. In future research the scale of this study might be expanded to more recent social marketing campaigns and, where possible, replicated a number of times before any further implications and conclusions can be made (Remenyi, et al., 1998: 36). 


\section{References}

Anand, C., \& Kumar, M. (1982). Developing a modernity attitude scale. Indian Educational Review, 17(3), $28-41$.

Australian Bureau of Statistics (ABS). (2004). Religious affiliation and activity, Catalogue Number 4102.0 Australian Social Trends, Canberra.

Australian Bureau of Statistics (ABS). (2006). Religious Affiliation, Catalogue Number 1301.0 - Year Book Australia, Canberra.

Birch, D., Schirato, T., \& Srivastava, S. (2001). Asia - Cultural Politics in the Global Age, Allen and Unwin, Sydney.

Creswell, J. W. (1998). Qualitative Inquiry and Research Design: Choosing among five traditions. Thousand Oaks, CA: Sage Publications, Inc.

Crotty, M. (1998). The foundations of social research: Meaning and perspective in the research process. Sydney, New South Wales, Australia: Allen and Unwin.

Fam, K. S., Waller, D. S., \& Erdogan, B. Z. (2004). The influence of religion on attitudes towards the advertising of controversial products. European Journal of Marketing, 38(5-6), 537-555. http://dx.doi.org/10.1108/03090560410529204

French, J., Blair-Stevens, C., Merritt, R., \& McVey, D. (2010). Social Marketing and Public Health: Theory and Practice. Oxford: Oxford University Press.

Greeley, A. (1977). The American Catholic. New York, NY: Basic Books.

Hirschman, E. (1983). Aesthetics, Ideologies, and the Limits of the Marketing Concept. Journal of Marketing, Summer, 45-55. http://dx.doi.org/10.2307/1251196

Jette, D., Grover, L., \& Keck, C. (2003). A Qualitative Study of Clinical Decision Making in Recommending Discharge Placement from the Acute Care Setting. Physical Therapy, 83, 224-236.

Kosmin, B. A., \& Keysar, A. (2008). American Religious Identification Survey, Summary Report, Trinity College Hartford Connecticut. $\quad$ Retrieved from http://www.americanreligionsurvey-aris.org/reports/ARIS_Report_2008.pdf

Kotler, P., \& Zaltman, G. (1971). Social marketing: An approach to planned social change. Journal of Marketing, 35, 3-12. http://dx.doi.org/10.2307/1249783

LaBarbera, P. (1987). Consumer behaviour and born again Christianity. Research in Consumer Behaviour, 2 , 193-222.

Luqmani, M., Yavas, U., \& Quraeshi, Z. (1987). Advertising in Saudi Arabia: content and regulation. International Journal of Advertising, 6(1), 59-71.

MacFadyen, L., Stead, M., \& Hastings, G. (1999). A synopsis of social marketing. Retrieved from http://www.ism.stir.ac.uk/pdf_docs/social_marketing.pdf

McDaniel, S., \& Burnett, J. (1990). Consumer religiosity and retail store evaluative criteria. Journal of the Academy of Marketing Science, 18(2), 101-112. http://dx.doi.org/10.1007/BF02726426

Michell, P., \& Al-Mossawi, M. (1999). Religious commitment related to message contentiousness. International Journal of Advertising, 18, 427-443.

Office for National Statistics (ONS), (2001). The UK population: by religion. Britain's 2001 Census. Retrieved from http://www.statistics.gov.uk/cci/nugget.asp?id=293

Perry, C. (1995). A Structured Approach to Presenting PhD Theses: Notes for candidates and their supervisors. ANZ Doctoral Consortium, University of Sydney, February.

Reiman, J. (1979). Research subjects, political subjects and human subjects. In C. Klockars \& F. O'Connor (Eds.), Deviance and Decency: the Ethics of Research with Human Subjects (pp. 33-57). Beverly Hills, California: Sage.

Remenyi, D., Williams, B., Money, A., \& Swartz, E. (1998). Doing Research in Business and Management, An Introduction to Process and Method. London: Sage. http://dx.doi.org/10.4135/9781446280416

Uppal, J. (1986). Hinduism and economic development in South Asia. International Journal of Social Economics, 13(3), 20-23. http://dx.doi.org/10.1108/eb014011 
Van Esch, P., \& Van Esch, L. (2013). Justification of a Qualitative Methodology to Investigate the Emerging Concept: The Dimensions of Religion as Underpinning Constructs for Mass Media Social Marketing Campaigns. Journal of Business Theory and Practice, 1(2), 214-243.

Van Esch, P., Overton, L., \& Van Esch, L. (2014). Mass Media Social Marketing Campaigns: A review. International Business Research, 7(6), 1-17. http://dx.doi.org/10.5539/ibr.v7n6p1

Van Esch, P., Van Esch, L., \& Cowley, J. (2013). The Dimensions of Religion as Underpinning Constructs for Mass Media Social Marketing Campaigns: An Emerging Concept. International Journal of Marketing Studies, 5(1), 96-106. http://dx.doi.org/10.5539/ijms.v5n1p96

Veal, A. J. (2005). Business Research Methods: A Managerial Approach (2nd ed.). Frenchs Forest, Australia: Pearson Education.

Waller, D. S., \& Fam, K. S. (2000). Cultural values and advertising in Malaysia: views from the industry. Asia Pacific Journal of Marketing and Logistics, 12(1), 3-16. http://dx.doi.org/10.1108/13555850010764613

\section{Copyrights}

Copyright for this article is retained by the author(s), with first publication rights granted to the journal.

This is an open-access article distributed under the terms and conditions of the Creative Commons Attribution license (http://creativecommons.org/licenses/by/3.0/). 